\title{
Education About Death and Dying During Surgical Residency
}

\author{
William Rappaport, MD, Tucson, Arizona, Christopher Prevel, MD, Ann Arbor, Michigan, Donald Witzke, PhD, \\ John Fulginiti, MA, Tucson, Arizona, Jeff Ballard, MD, Thomas Wachtel, MD, Phoenix, Arizona
}

D espite great technical advances in medicine, it is estimated that between $60 \%$ to $80 \%$ of all deaths will take place in the hospital [1-3]. Over the past two decades, the education of health care professionals in the area of death and dying has received considerable attention, and at the present time, most medical schools provide instruction in this area $[4,5]$.

Little attention has been given, however, to education about death and dying during internship and residency years. This study was undertaken to evaluate surgical residents' attitudes, experience, and education in caring for terminally ill patients.

From September 1989 to January 1990, a questionnaire concerning the care of terminally ill patients was distributed to all three general surgical residency training programs in the state of Arizona. A total of 83 questionnaires were distributed, of which $53(64 \%)$ were returned.

The questionnaire asked for certain demographic information including age, sex, and year of surgical training. The remaining questions involved three general areas: (1) experience, (2) attitude, and (3) education in caring for terminally ill patients. Junior residents (Group 1) consisted of first- and second-year residents while senior residents (Group 2) were at their third-year level of training or greater. Statistical analysis was performed using chi-square.

Of the 53 surgical residents responding, there were 42 men and 11 women with a mean age of 28 years. Group 1 consisted of 25 residents and Group 2, 28 residents. All housestaff questioned had cared for terminally ill patients and had discussed with a dying patient the patient's prognosis. The mean number of terminally ill patients cared for per month by each surgical resident was 2.6 . Seventyfour percent of surgical residents believed strongly that patients should be told if they have a terminal illness; however, $42 \%$ of respondents believed that less than half of all terminally ill patients wish to discuss the fatality of their illness.

From the Department of Surgery (WR) and the Division of Academic Resources (DW, JF), University of Arizona Medical Center, Tucson, Arizona; and the Departments of Surgery, University of Michigan, Ann Arbor, Michigan (CP), and Mancopa Medical Center (JB) and Good Samaritan Hospital (TW), Phoenix, Arizona.

Requests for reprints should be addressed to William Rappaport, MD, University of Arizona, Department of Surgery, Room 5411, 1501 North Campbell Avenue, Tucson, Arizona 85724.

Manuscript submitted June 14, 1990, and accepted in revised form September 12, 1990.
Table I reveals responses regarding the resident-patient and the resident-family interactions. Time constraints were cited as a major factor limiting the time residents could spend with terminally ill patients and their families.

Fifteen (28\%) residents did not routinely involve any ancillary help (i.e., social services, home health nurses, self-help groups) when discharging a terminally ill patient home. Based on the work of other authors $[2,6,7]$, common problems encountered by the relative caring for a terminally ill patient as well as patients' fears on being discharged home were recorded (Table II). Seventeen percent of the residents responding could name two or more problems likely to be encountered by family members, and $33 \%$ of respondents could name two or more of patients' fears on being discharged home. When Groups 1 and 2 were compared, there was no statistical difference in response for any of the above-named questions.

Two thirds of the residents had prior education in caring for terminally ill and dying patients in medical school. Table III illustrates education about death and dying during surgical residency by attending surgeons. Senior residents were involved more often with the attending surgeon when they talked with a dying patient compared with junior residents $(p<0.05)$. In addition, in Group 2, 50\% of the residents had discussed with the attending surgeon how to deal with a terminally ill patient, versus only $16 \%$ in Group $1(\mathrm{p}<0.05)$. When asked if they would be well prepared to care for terminally ill patients after finishing residency, eight (32\%) residents in Group 1 and six (21\%) in Group 2 responded negatively. Overall, $79 \%$ of the residents welcomed an opportunity to be formally educated in this area during residency.

At present, most deaths in the United States take place in the hospital [1-3], with residents and interns often intimately involved with caring for these patients and interacting with their families. In our study, the majority of surgical residents indicated a preference for telling patients if they had a fatal illness. This finding is consistent with that of other investigators who have noted a dramatic change in physicians' willingness to tell their patients if they had a poor prognosis [8]. There is a growing body of opinion that patients should be informed of their condition for both moral and practical management reasons $[7,9]$. Although most residents favored being candid with their patients regarding their diagnosis, less than half believed that terminally ill patients wished to discuss their illness with their physician. This contrasts with the work of Kübler-Ross [7] who reported that a substantial majority of dying patients asked, wished to discuss their illness with their doctors but often were afraid to initiate the discussion. 
The majority of residents believed that they spent the same amount of time or more time with terminally ill patients and/or patients with "do not resuscitate" orders in the event of cardiac or pulmonary arrest. This subjective appraisal is contrary to the observation of Knight and Field [9] who observed that surgeons spent considerably less time with their terminally ill patients than with other postoperative patients who were expected to fully recover.

The interaction of the surgical residents with families of terminally ill patients was disappointing and did not improve during the senior years of residency. Sixty-one percent of senior surgical residents did not routinely advise families on the major problems likely to be encountered by their dying relative, nor did they recognize the problems family members might encounter in caring for the terminally ill patient at home. This problem of physician-family interaction has been noted by others $[7,9]$. Communicating with the family of the dying patient is often very stressful as family members are frequently depressed, anxious, and often extremely angry. Interaction under these circumstances requires time and understanding. As noted in our study, work constraints often limit the amount of time surgical residents can spend with the families of terminally ill patients. Family involvement in patient care discussions, as well as education of close relatives in the psychosocial aspects of death and dying, is crucial to their well being as well as that of the patients. As Kübler-Ross notes, before a patient can feel comfortable talking about and accepting death, their loved ones must also go through a stage of acceptance [7].

On discharging terminally ill patients home, less than half of the senior or junior residents knew of the problems that the patient or family would encounter. Also, ancillary help was often not utilized. It is clear that most patients prefer to die at home and their spouse and/or relatives also prefer this [10]. However, as Bowling [6] points out, many of the relatives providing home care for patients with terminal illness are not receiving adequate support. Often, the support is available but the relatives as well as the physicians are ignorant of how to obtain help $[2,6]$. Social service personnel are well educated in this area and should be involved in discharge planning. Home health nursing care as well as support groups are also potential sources of support on discharging terminally ill patients home and should be utilized.

Although most of our surgical residents had a brief exposure to death education in medical school, it has been estimated that $30 \%$ to $60 \%$ of physicians learn to cope with and care for dying patients during residency [10]. Despite this fact, few residencies have formal education in death and dying. The experienced attending surgeon offers an excellent potential role model for educating the residents in this area.

Most of our surgical residents welcomed the opportunity for formal education in dealing with terminal illness. Exposure to brief formal courses as well as involvement and participation of house officers in a scheduled multidisciplinary conference on the care of dying patients whom they are currently treating may help formalize their attitudes in this important area. Ultimately, it is the patient who is our teacher if we make the time and effort

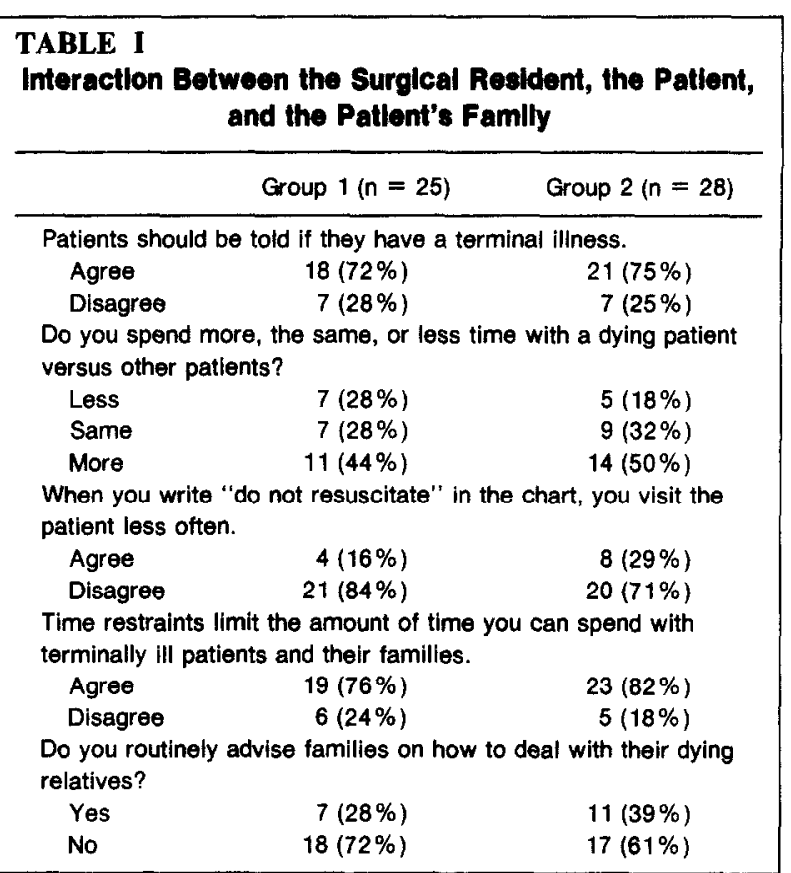

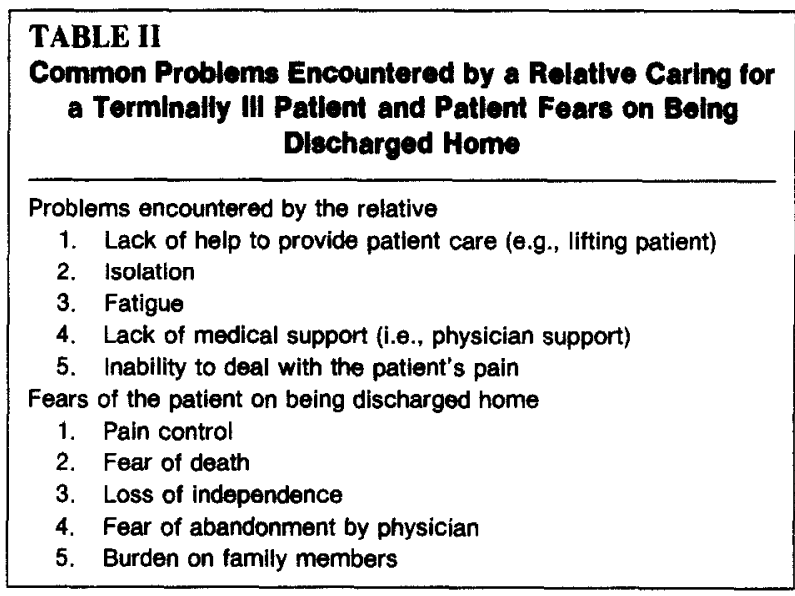

\begin{tabular}{|c|c|c|}
\hline \multicolumn{3}{|c|}{$\begin{array}{l}\text { TABLE III } \\
\text { Education About Death and Dying During Surgical } \\
\text { Residency }\end{array}$} \\
\hline & Group 1 & Group 2 \\
\hline \multicolumn{3}{|c|}{$\begin{array}{l}\text { How often are you involved with the attending surgeon when he } \\
\text { or she talks with a dying patient? }\end{array}$} \\
\hline$\geq$ Once per month & $9(36 \%)$ & $16(57 \%)^{*}$ \\
\hline <Once per month & $16(64 \%)$ & $12(43 \%)$ \\
\hline \multicolumn{3}{|c|}{$\begin{array}{l}\text { Has an attending surgeon ever discussed with you how they dea } \\
\text { with a terminally ill patient? }\end{array}$} \\
\hline Yes & $4(16 \%)$ & $14(50 \%)^{*}$ \\
\hline No & $21(84 \%)$ & $14(50 \%)$ \\
\hline
\end{tabular}

to listen. As Kübler-Ross states: "Those who attempt to care for the terminally ill patients can learn from the patients; the patients become our teachers [7]." 


\section{REFERENCES}

1. Rees WD. Role of the hospice in the care of the dying. BMJ 1982; 285: 1766-8.

2. Haines A, Booroff A. Terminal care at home: perspective from general practice. BMJ 1986; 292: 1051-4.

3. Herman TA. Terminally ill patients. NY State J Med 1980; 80: 200-7.

4. Bleeker JA, Pomerantz HB. The influence of a lecture course in loss and grief on medical students: an empirical study of attitude formation. Med Educ 1979; 13: 117-28.

5. Howells K, Field D. Fear of death and dying among medical students. Soc Sci Med 1982; 16: 1421-4.
6. Bowling A. The hospitalization of death: should more people die at home? J Med Ethics 1983; 9: 158-61.

7. Kübler-Ross E. On death and dying. New York: Macmillan, 1970 .

8. Blumenfield M, Levy N, Kaufman D. Current attitudes of medical students and house staff toward terminal illness. Gen Hosp Psychiatry 1979; 22: 306-10.

9. Knight M, Field D. A silent conspiracy: coping with dying cancer patients on an acute surgical ward. J Adv Nurs 1981; 6 : 221-9.

10. Kalish R, Reynolds D. Death and ethnicity: a psycho-cultural study. Los Angeles: University of Southern California Press, 1976. 